\title{
SVN Jisuma \\ Trend of declining stroke mortality in China: reasons and analysis
}

To cite: Wang W, Wang D, Liu $\mathrm{H}$ et al. Trend of declining stroke mortality in China: reasons and analysis. Stroke and Vascular Neurology 2017;2: e000098. doi:10.1136/svn-2017-000098

Received 24 May 2017 Accepted 8 June 2017 Published Online First 20 June 2017

\section{CrossMark}

${ }^{1}$ Beijing Neurosurgical Institute, Capital Medical University, Beijing, China

${ }^{2}$ Beijing Municipal Key Laboratory of Clinical Epidemiology, Beijing, China ${ }^{3}$ Department of Neurology, OSF/INI Comprehensive Stroke Center at SFMC, University of Illinois College of Medicine at Peoria, Illinois, USA

${ }^{4}$ Beijing Tiantan Hospital, Capital Medical University, Beijing Institute for Brain Disorders, Beijing, China

Correspondence to Dr Wenzhi Wang, Beijing Neurosurgical Institute, Capital Medical University; qgnfbwwz@163.com

\section{ABSTRACT}

Introduction There is a downward trend of stroke-related mortality in the USA. By reviewing all published articles on stroke mortality in China, we analysed its trend and possible factors that have influenced the trend.

Methods Both English and Chinese literatures were searched on the mortality of stroke or cerebrovascular diseases in China. Potential papers related to this topic were identified from PubMed, Medline, Embase, Cochrane Library, Wanfang Database, SINOMED and China National Knowledge Infrastructure databases.

Results Comparing the results from the most recent population-based epidemiological survey and databank from the national Center for Disease Control and Prevention, the age-adjusted stroke mortality rate has shown a downward trend among both urban and rural population in the past 30 years in China. Comparing with 30 years ago, the rate of stroke mortality has decreased by more than $31 \%$ in urban/suburban population and $11 \%$ in rural population. In men, the age-adjusted stroke mortality rate decreased by $18.9 \%$ and in women by 24.9\% between 1994 and 2013. Factors that may have contributed to the trend of decreased stroke mortality rate include (1) improved healthcare coverage and healthcare environment; (2) improved treatment options and medical technology; (3) support by government to educate the public on stroke and stroke prevention; and (4) improved public knowledge on stroke.

Conclusions The age-adjusted stroke mortality rate in China has shown a downward trend among both urban and rural population in the past 30 years. The major influencing factors that helped in reducing stroke mortality in China included improved healthcare coverage, healthcare environment, the updated treatment options and modern medical technology.

\section{INTRODUCTION}

Stroke is the second leading cause of death above the age of 60 years and the fifth leading cause of death in people aged 15-59 years old in the world. ${ }^{1}$ In China, about 2.4 million people have a new stroke each year, ${ }^{2}$ and $75 \%$ live with varying degrees of disability from stroke. ${ }^{3}$ However, in several Western countries such as the USA, the age-adjusted mortality rate of stroke has decreased by $37 \%$ from 1999 to 2009. ${ }^{4}$ In China, even with increased stroke incidence, stroke mortality rate has also been decreased in the past decades. In
2005, stroke was found to be the first leading cause of death in the third national survey on all causes of death. ${ }^{5}$ Then, what was the trend in stroke mortality in China over the past 30 years? Was it trending up or down? By reviewing all published articles on stroke mortality in China, we analysed its trend and possible underlying factors that have influenced the trend.

\section{METHODS}

Both English and Chinese literatures were searched on the mortality of stroke or cerebrovascular diseases in China. Potential papers related to this topic were identified from PubMed, Medline, Embase, Cochrane Library, Wanfang Database, SINOMED and China National Knowledge Infrastructure databases. The reference lists of all relevant studies and reviews were also checked in order to identify any pertinent information. Our search strategy consisted of MeSH terms and the following keywords: stroke mortality, cerebral vascular disease mortality, death from stroke or death from cerebral vascular disease in Chinese or China. Published data were tabulated based on their different variables. Reported rates on the mortality of stroke were tabulated and analysed.

\section{RESULTS}

Data from the national population-based epidemiological study

The results from the national epidemiological survey of stroke in China in 2013 were published in Circulation at the beginning of 2017. ${ }^{2}$ The survey was implemented and conducted by the Beijing Neurosurgical Institute and the National Office for Cerebrovascular Disease Prevention and Control, National Health and Family Planning Commission of China, and the Chinese Center for Disease Control and Prevention (CDC), and supported by the Ministry of Science and Technology. It was conducted at 157 national disease monitoring sites in 31 
provinces (autonomous regions and directly governed municipalities) using multistage stratified clusters sampling method. The sampling was calculated according to a $1 \%$ prevalence rate of stroke, which required a total of 600000 populations (across all ages) that should be surveyed. This study project was completed by two teams in two steps. The first step was the screening, completed by the investigators at the CDC of provincial and district/ county level. The second step was an onsite visit of those who were diagnosed with either a stroke, possible stroke or died from stroke from 1 September 2012 to 31 August 2013 by the local neurologists. This method helped to ensure the accuracy and reliability of the study results.

Death due to stroke was determined according to the following criteria: patient's history, imaging test results and hospital records when alive, or the death certificate. In addition, entry would be confirmed if one of the following criteria was met: (1) bedridden after stroke and died from infection or organ failure; (2) dysphagia after stroke and died from aspiration pneumonia; (3) death from recurrent stroke; and (4) death from complications such as pneumonia, gastrointestinal haemorrhage, cardiopulmonary failure and so on. Those who have had partial recovery from stroke but died from other known causes, such as suicide, motor vehicle accident or cancer, were excluded from this survey. For those cases that had no clear medical history, or a diagnosis of death from old age or unclear causes, two neurologists would adjudicate their causes of death.

To determine the death attributable to stroke, the investigator obtained information by an onsite visit and combined it with the data on the causes of stroke. Onsite review was required by neurologists so that all documented deaths from 1 January 2012 to the day of the survey could be accurately recorded. The statistical analysis was performed on the mortality data obtained between 1 September 2012 and 31 August 2013. The mortality rate was calculated as the total number of death/average number of population during that period. Table 1 shows the total (cross all ages) mortality of stroke. Of all population investigated (595711 people), the overall crude mortality rate was $127.2 / 100000$ (95\% CI 118.2 to 136.3 ), and the weighted mortality rate was $85.9 / 100000(95 \%$ CI 71.8 to 100.1 ). Among them, the crude mortality rate for men was $139.1 / 100000$ (95\% CI 125.8 to 152.5 ), and the weighted mortality rate was 90.0/100 000 (95\% CI 72.8 to 107.3$)$. In women, the crude mortality rate of stroke was $115.2 / 100000$ (95\% CI 103.0 to 127.4), and the weighted mortality rate was 81.6/100000 (95\% CI 64.5 to 98.8 ). The age-adjusted stroke mortality rate (age-adjusted by the WHO world population) in rural areas was $116.8 / 100000$, significantly higher than that in the urban areas, which was $74.9 / 100000$.

Table 2 lists the weighted mortality rate of stroke in adults ( $\geq 20$ years) in 31 provinces in China. The top three provinces with the highest stroke mortality rate were Liaoning province (282.0/100 000), city of Tianjin (260.5/100000) and Hubei province (211.9/100000).
The two regions with the lowest stroke mortality rate were Shanghai $(7.3 / 100000)$ and Hainan province $(8.5 / 1000000)$.

\section{Early data from the population-based survey}

In 1980s, several large-scale, cross-sectional, population-based surveys on stroke were conducted. ${ }^{67}$ These surveys were also conducted by onsite visit by neurologists. The methodology and the way to define stroke mortality were similar to the study employed in 2013. However, in 1980s, CT scan was just introduced to China and the diagnosis of stroke was mostly based on clinical findings. Therefore, the accuracy in stroke classification was lacking. In the 2013 survey, over $90 \%$ of patients with stroke had imaging examinations, which helped with the diagnostic accuracy, better stroke classification and determination of the cause of death from stroke.

In 1983, the survey of six Chinese cities (63195 people) showed that the age-adjusted mortality rate of stroke (age-adjusted by WHO world population $)^{8}$ was about $108.5 / 100000$. In 1985, the survey of rural areas in 22 provinces (246812 people) showed that the age-adjusted mortality rate of stroke was $131.8 / 100000$. In 2013, the survey in urban residents showed that the age-adjusted mortality rate of stroke was 74.9/100000. To compare the two different rates of stroke mortality from these two different periods, it appeared that stroke mortality rate in China was lowered by $31.0 \%$ (six cities 30 years ago). ${ }^{5}$ The 2013 survey also showed that the age-adjusted stroke mortality rate in all ages of residents in rural areas was $116.8 / 100000$, a $11.4 \%$ decrease compared with 30 years ago (figure 1).

In 1985, the other large-scale, population-based study on stroke mortality was conducted by the Armed Forces Epidemiology Research Group. It was a cross-sectional onsite survey of 5814851 people, which showed a stroke mortality rate of $77.2 / 100000 .{ }^{9}{ }^{10}$ Since the sample size was too large, quality control of the survey was difficult. This might have contributed to the findings of lower rate of stroke prevalence, incidence and mortality than those in the other surveys during the same period in 1980s.

Since 1970s, the Ministry of Health of China has organised three national retrospective surveys of the causes of death. The second survey was completed during 19901992 and the third one between 2004 and 2005. ${ }^{4}$ The survey recorded the findings based on findings from a combined search by clue and onsite visit findings. The second survey (1990-1992) found the stroke death rate (crude) was about 101.93/100000, age-adjusted (by China census population 1982) was $84.54 / 100000$. At that time, cerebrovascular disease was the third leading cause of death in China. However, the third national survey (2004-2005) revealed that the stroke death rate (crude) was $136.64 / 100000$, age-adjusted to $81.19 / 100000$. It was this survey that has found cerebrovascular disease or stroke had become the leading cause of death in China (table 3). 


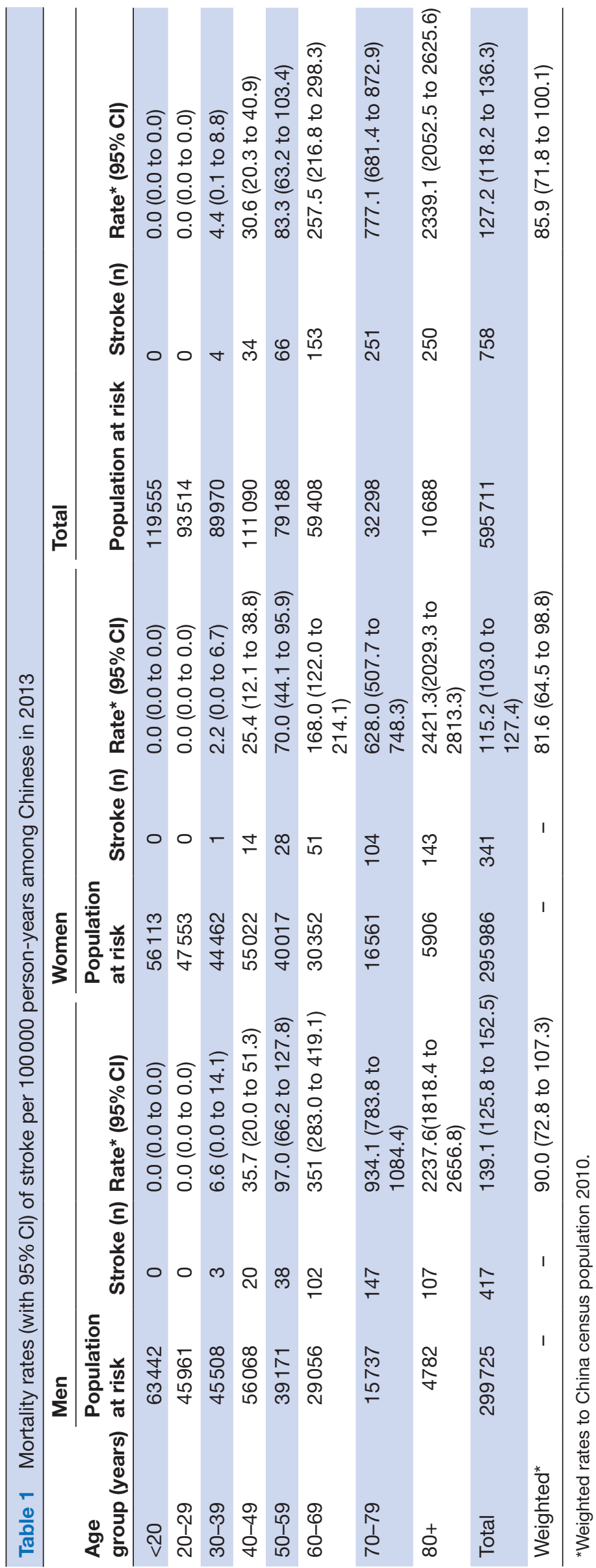


Table 2 Mortality rates (with 95\% Cl) of stroke per 100000 person-years among adults ( $\geq 20$ years) in 31 provinces of China

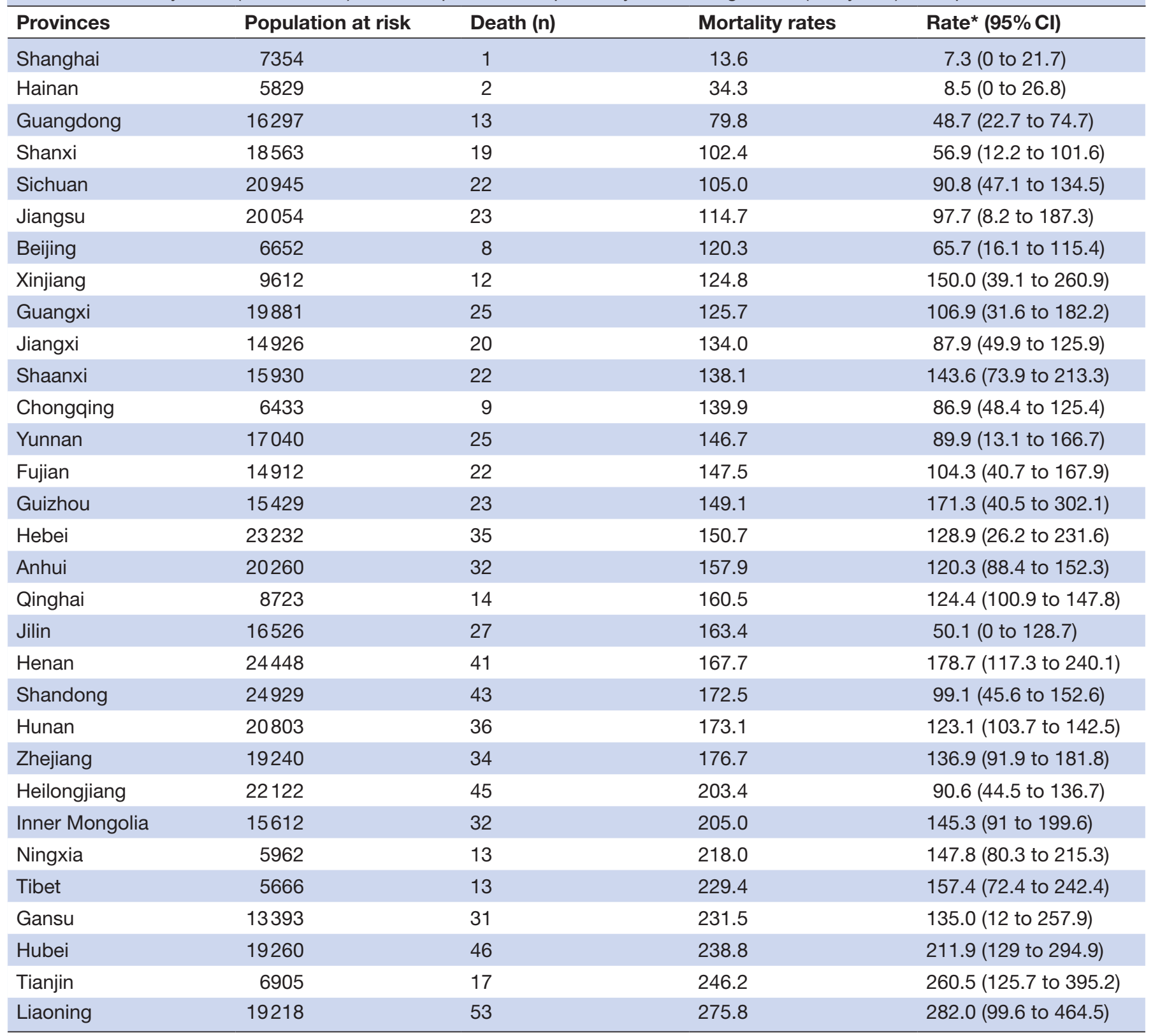

*Weighted rates to China census population 2010.

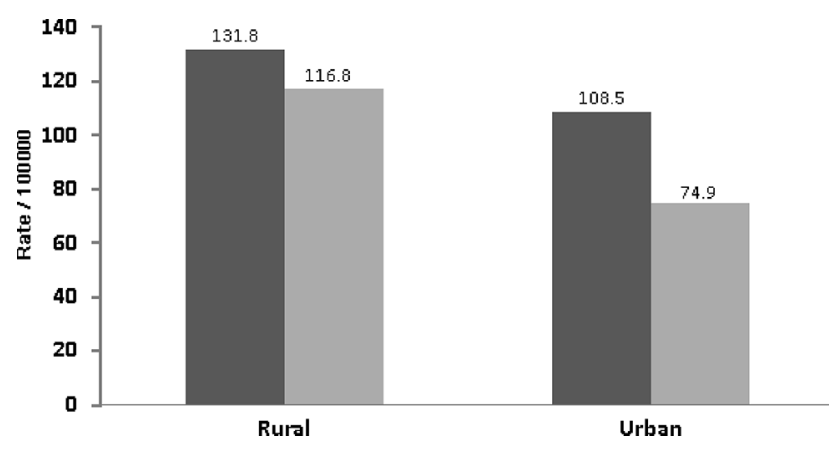

Figure 1 Age-standardised mortality of stroke in rural and urban areas of China compared between the survey in 2013 and 1983-1985.
Data from the national disease surveillance system on stroke mortality

Filing a report on death began in 1980s in China. There were two systems: the national disease surveillance points (DSP) and registry on cause of death by the Ministry of Health at that time.

The DSP system began in early 1980s. Professor He Guan-qing, a well-known epidemiologist, established a few pilot surveillance sites in the Dongcheng District of Beijing and Tongxian county. Surveillance sites were increased to 71 in 29 provinces (autonomous zone and municipality) in 1989. The project later became the official national DSP. In 1990, with the support from the World Bank, the Chinese Academy of Preventive Medicine employed multistage stratification random sampling 
Table 3 Death rates of six main diseases in the second (1990-1992) and the third survey of the causes of death (2004-2005) in China

\begin{tabular}{|c|c|c|c|c|c|c|c|c|}
\hline \multirow[b]{2}{*}{ Rank } & \multicolumn{4}{|l|}{ 1990-1992 } & \multicolumn{4}{|l|}{ 2004-2005 } \\
\hline & Disease & $\begin{array}{l}\text { Death } \\
\text { rate }\end{array}$ & $\begin{array}{l}\text { Age- } \\
\text { standardised* } \\
\text { rate }\end{array}$ & $\begin{array}{l}\text { Percentage } \\
\text { in all deaths }\end{array}$ & Disease & $\begin{array}{l}\text { Death } \\
\text { rate }\end{array}$ & $\begin{array}{l}\text { Age- } \\
\text { standardised* } \\
\text { rate }\end{array}$ & $\begin{array}{l}\text { Percentage } \\
\text { in all deaths }\end{array}$ \\
\hline 1 & $\begin{array}{l}\text { Diseases of the } \\
\text { respiratory system }\end{array}$ & 137.52 & 115.47 & 22.79 & $\begin{array}{l}\text { Cerebrovascular } \\
\text { disease }\end{array}$ & 136.64 & 81.19 & 22.45 \\
\hline 2 & $\begin{array}{l}\text { Malignant } \\
\text { neoplasms }\end{array}$ & 108.26 & 94.22 & 17.94 & $\begin{array}{l}\text { Malignant } \\
\text { neoplasms }\end{array}$ & 135.88 & 91.24 & 22.32 \\
\hline 3 & $\begin{array}{l}\text { Cerebrovascular } \\
\text { disease }\end{array}$ & 101.93 & 84.54 & 16.89 & $\begin{array}{l}\text { Diseases of } \\
\text { the respiratory } \\
\text { system }\end{array}$ & 96.28 & 56.27 & 15.81 \\
\hline 4 & Injury and poisoning & 66.16 & 61.44 & 10.97 & Heart disease & 90.23 & 52.2 & 14.82 \\
\hline 5 & Heart disease & 52.70 & 43.84 & 8.73 & $\begin{array}{l}\text { Injury and } \\
\text { poisoning }\end{array}$ & 61.51 & 49.48 & 10.10 \\
\hline 6 & $\begin{array}{l}\text { Diseases of the } \\
\text { digestive system }\end{array}$ & 30.37 & 26.5 & 5.03 & $\begin{array}{l}\text { Diseases of the } \\
\text { digestive system }\end{array}$ & 16.78 & 11.14 & 2.76 \\
\hline
\end{tabular}

*Age-standardised by China census population 1982.

process and built representative sampling sites in 31 provinces, municipalities and autonomous zones, and formed systematically 145 DSPs. This new DSP system covers 10 million populations and routinely collects data on any birth and mortality (about $1 \%$ of Chinese population). In 2003, the DSP system was expanded to 160 sites and covered 70 million populations. ${ }^{11}$

The Ministry of Health became responsible for all mortality registries in 1987. After 2000, this registry covered 90 counties in 15 provinces and eastern rural areas of China, about 100 million people, $8 \%$ of the Chinese population. Among them, $50 \%$ lived in the eastern area, $40 \%$ in central China and only $10 \%$ in the western region. The statistical centre at the Ministry of Health would collect and analyse the mortality rate of all kinds of diseases annually.

Recently, based on the data on global disease burden in 2013 (data from Chinese DSP system of CDC), Wang et $a l^{12}$ from the School of Public Health of Wuhan University published in Stroke about the downward trend of stroke mortality among different age-adjusted groups in China from 1994 to 2013. Overall, in 20 years, stroke mortality decreased by $18.9 \%$ in men, but increased a little after 2010. In women, stroke mortality showed a consistent downward trend, decreased by $24.9 \%$ (figure 2). Professor GH Yang of the Chinese CDC stated that the age-adjusted stroke mortality rate was about $167.0 / 100000$ in 1990 and decreased to $126.8 / 100000$ by 2010. In this report, the mortality from ischaemic stroke was markedly less than that from intracerebral haemorrhage. Among them, the age-adjusted mortality rate of ischaemic stroke was 56.3/100000 in 1990 and reduced to $46.7 / 100000$ in 2010. Mortality from intracerebral haemorrhage was $110.7 / 100000$ in 1990 and dropped to $80.2 / 100000$ in $2010 .{ }^{13}$ However, the other Chinese CDC document reported that the age-adjusted stroke mortality rate was $199.7 / 100000$ in 1990 and reduced to $157.3 / 100000$ in 2013. Among them, death from ischaemic stroke was 51.6/100000 in 1990 but increased to $62.9 / 100000$ in 2013 . Death related to intracerebral haemorrhage was 148.1/100 000 in 1990 and dropped to 94.4/100 000 in 2013. ${ }^{14}$ Although both documents came from Chinese CDC, there was a significant discrepancy between the two. The Statistical and Information Center of the Ministry of Health reported stroke mortality from the survey results of 36 cities and 80 counties in China from 1990 to 1998. During this period, the age-adjusted (by China census population 1982) stroke mortality among the urban residents was $84.11 / 100000$ and $74.05 / 100000$ in rural areas. ${ }^{15}$ During a 9-year period, stroke mortality in urban areas was showing a downward

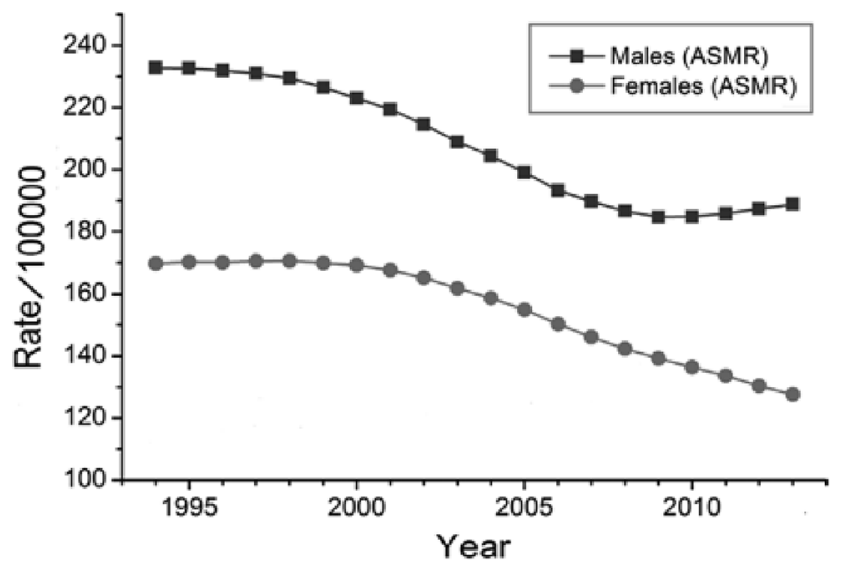

Figure 2 Trends of ASMR of stroke by sex in China, 19942013. ASMR, age-standardised mortality rates; CMR, crude mortality rate. (This figure is partly quoted from published paper Wang et al. ${ }^{12}$ ) 


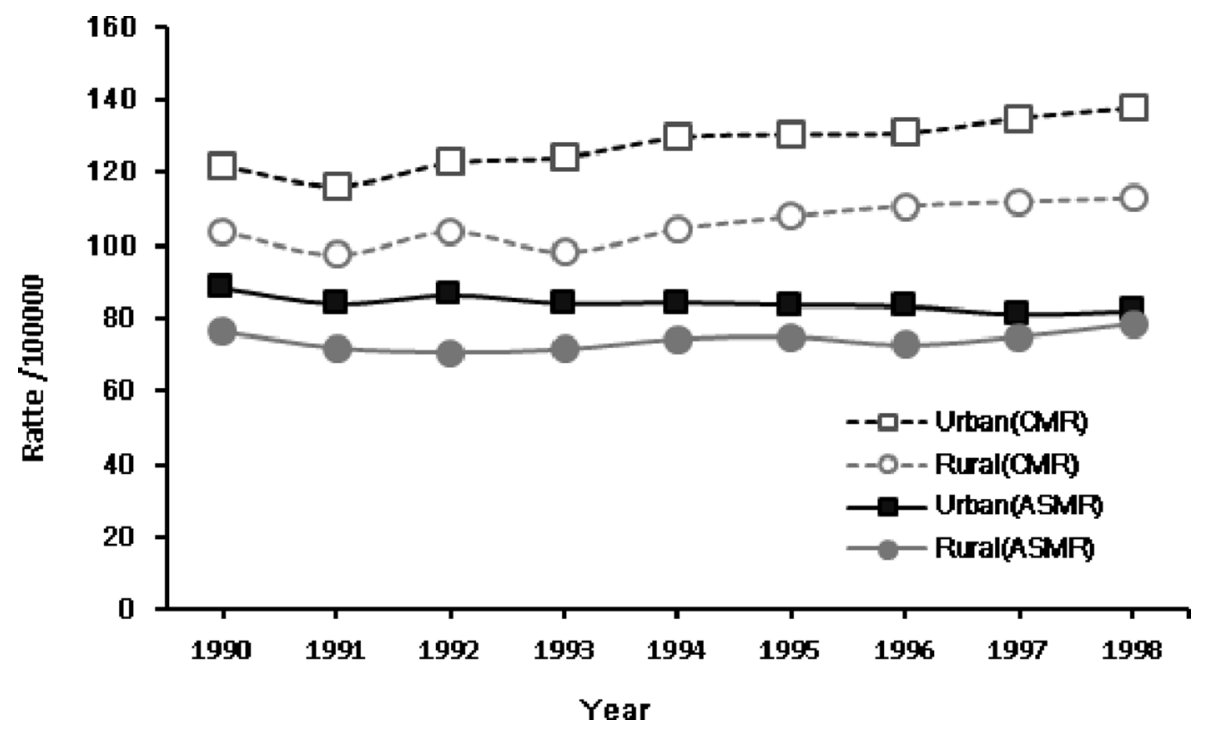

Figure 3 Trends of the crude mortality rates and the age-standardised mortality rates (ASMR) per 100000 population for stroke in urban and rural in China, 1990-1998.

trend, but in rural areas it was showing a slightly upward trend (figure 3).

\section{Data from the Monitoring Trend and Determinants in}

Cardiovascular Disease (MONICA) study

Designed by the expert group of WHO, the MONICA study was a project to monitor the trend of cardiovascular disease and stroke incidence and mortality in different countries. The MONICA study in China monitored people between the ages of 35 and 64 in 17 provinces from 1987 to 1993 and found that the mortality rate varied significantly. Anhui province had the lowest male stroke mortality rate at 27.0/100 000 . The highest rate was in the province of Heilongjiang, at 107.3/100000. Fujian province had the lowest stroke mortality rate in women at 14.0/100 000. Overall, stroke mortality rate did not change significantly between 1987 and $1993 .^{16}$

\section{DISCUSSION}

Literature has reported that in countries of high income, age-adjusted stroke mortality rate has decreased by $37 \%$ in the past 20 years. ${ }^{17}$ In America, age-adjusted stroke mortality rate has always shown a declining trend in the past 50 years. Stroke has dropped down to be the fourth common death of diseases. ${ }^{18}$ The 2013 scientific statement by the AHA/ASA mentioned that the factors that have caused the lower stroke mortality rate included lower incidence of stroke and fewer people dying from stroke. Looking back to 1970 s, the strategy of controlling blood pressure better probably had the biggest impact on stroke mortality. Tightly controlling other risk factors such as diabetes and hyperlipidaemia, lowering rate of smoking, together with blood pressure control have all helped in lowering stroke mortality in the USA.

In China, the research on this newly discovered lowering trend in stroke mortality is lacking. It is even more difficult to explain why stroke has become the leading cause of death in China since 2005 while the report on stroke mortality has shown a downward trend over the past 30 years. Nevertheless, we have postulated the following possible explanations:

\section{The improvement of overall healthcare conditions in China} Improvement in healthcare environment and technology are two important factors that lowered stroke mortality in China. In the past 30 years, Chinese economy has had rapid growth. Healthcare access has continued to improve among urban and rural residents. The new healthcare insurance plan for the rural area helped rural residents get treated much more readily. Parry ${ }^{19}$ reported that the health insurance coverage in China has increased from $45 \%$ in 2006 to around $90 \%$ in 2009 . With the improved healthcare insurance coverage, more patients with stroke could get timely treatment in the hospital, which would reduce poststroke complications and death.

Hypertension is considered the silent killer since it is the most important risk factor for all vascular diseases including stroke. A report by Liao $e t a t^{20}$ showed that in China, treatment rates among those diagnosed with hypertension have increased to around $90 \%$ by 2009 . And such improved awareness was more prominent in elderly.

\section{Advancement of the clinical diagnosis and treatment technology}

Significant improvements on techniques for diagnosis, treatment and management, accompanied by more and better healthcare professionals, played a critical role in the decline of case fatality of stroke, and thus lowered the overall stroke mortality. ${ }^{12}{ }^{21}$ Data from the Chinese National Stroke Registry showed that during the beginning stage of offering intravenous rt-PA treatment to patients with acute ischaemic stroke, about one in five patients had the treatment if they presented within 3 hours. ${ }^{22}$ Early treatment has translated into improved 
neurological outcome and hence lowered mortality of stroke. In recent years, the number of patients with acute ischaemic stroke treated with intravenous rt-PA has increased, especially in many cities in China. In addition, the establishment of stroke unit has improved stroke care and might have contributed to lowered stroke mortality. A cross-sectional survey in 2004 revealed that $7.4 \%$ of the 124 hospitals have established stroke units in Beijing. The report also stated that at the time of survey, around 300 stroke units have been established across the country. ${ }^{23} 24$

Many county hospitals in rural areas have started to offer intravenous thrombolysis to treat acute ischaemic stroke. In the past 20 years, a new treatment technique, minimally invasive transcranial needle aspiration of haematoma for patients with intracerebral haemorrhage, has been widely implemented in China. ${ }^{25}$ By the end of 2013, nearly 10000 neurosurgeons, neurologists and doctors working at local emergency rooms (ERs) were trained on this technique, which has benefited more than one million patients with intracerebral haemorrhage. ${ }^{26}$

\section{The decline of stroke incidence in urban residents and} epidemiological transition of stroke subtype in China

The current (2013) study has found that stroke incidence was higher than the findings in previous surveys in China, even substantially increased in rural areas over the last three decades. However, in urban residents, the age-adjusted incidence of stroke (168.2/100000) declined significantly than that in the 1983 survey $(205.4 / 100000)$, a decrease by $18.1 \%$. This must have had a significant impact on the decline of stroke mortality in China.

A prospective population-based registry showed that the incidence of ICH has decreased significantly at a rate of $12.0 \%$ per year in Beijing, $4.4 \%$ in Shanghai and $7.7 \%$ in Changsha during the $1990 \mathrm{~s}$, although the incidence of ischaemic stroke has increased in Beijing (5.0\% per year) and Shanghai $(7.7 \%) .{ }^{27}$ In recent times, the prevalence of obesity, hypertension, diabetes and hypercholesterolaemia in Chinese populations has increased because of increased calorie intake, alcohol consumption, cigarette smoking and reduced physical activity. There is a trend of stroke epidemiological transition, with increased IS and decreased ICH in China. This trend might have also played a role in the decline of stroke mortality over the past 30 years in both urban and rural areas.

\section{The impact on improvements of stroke knowledge}

Improved stroke education and awareness of stroke in the past 30 years have helped in reducing stroke mortality. The Chinese government has invested heavily in the prevention and treatment of non-communicable diseases, which has rapidly improved the healthcare conditions and upgraded technology for all levels of healthcare institutions. Modern stroke prevention and treatment guidelines have facilitated the standardisation of stroke care for physicians and improved their skills. ${ }^{28}{ }^{29}$ Furthermore, public knowledge on stroke prevention and seeking timely treatment when stroke strikes have improved significantly in China. Currently, there is ongoing national campaign to shorten the prehospital delay of recognising stroke, transporting patient to the nearest ER, and treatment with intravenous thrombolysis and intra-arterial thrombectomy. It is likely that with improved public knowledge on stroke, fast transport of stroke patient and expedited treatment, stroke mortality rate may decrease further in China.

\section{CONCLUSION}

From the results obtained in the most current population-based epidemiological survey and data from the national $\mathrm{CDC}$, the age-adjusted stroke mortality rate has shown a downward trend among both urban and rural population in the past 30 years. Comparing with 30 years ago, the rate of stroke mortality has decreased by more than $31 \%$ in urban/suburban population and $11 \%$ in rural population. In men, the age-adjusted stroke mortality rate decreased by $18.9 \%$ and in women by 24.9\% between 1994 and 2013.

Factors that may have contributed to the trend of decreased stroke mortality rate in the past $20-30$ years in China include (1) improved healthcare coverage and healthcare environment; (2) improved treatment options and medical technology; (3) support of government to educate the public on stroke prevention; and (4) better public knowledge on stroke. More research is needed to monitor the trend of stroke mortality in China.

Correction notice This paper has been amended since it was published Online First. Owing to a scripting error, some of the publisher names in the references were replaced with 'BMJ Publishing Group'. This only affected the full text version, not the PDF. We have since corrected these errors and the correct publishers have been inserted into the references.

Competing interests None declared.

Provenance and peer review Commissioned; internally peer reviewed.

Open Access This is an Open Access article distributed in accordance with the Creative Commons Attribution Non Commercial (CC BY-NC 4.0) license, which permits others to distribute, remix, adapt, build upon this work non-commercially, and license their derivative works on different terms, provided the original work is properly cited and the use is non-commercial. See: http://creativecommons.org/ licenses/by-nc/4.0/

(C) Article author(s) (or their employer(s) unless otherwise stated in the text of the article) 2017. All rights reserved. No commercial use is permitted unless otherwise expressly granted.

\section{REFERENCES}

1. World Heart Federation http://www.world-heart-federation.org/ cardiovascular-health/stroke

2. Wang W, Jiang B, Sun $\mathrm{H}$, et al. Prevalence, incidence, and mortality of stroke in China: results from a nationwide population-based survey of 480687 Adults. Circulation 2017;135:759-71.

3. Sun J, Guo Y, Wang X, et al. mHealth for Aging China: opportunities and challenges. Aging Dis 2016;7:53-67.

4. Centers for Disease Control and Prevention, National Center for Health Statistics. Compressed Mortality File 1999-2009. CDC WONDER Online Database, compiled from Compressed Mortality File 1999-2009 Series 20 No. 20, 2012. 2012 http://wonder.cdc.gov/ cmf-icd10.html (accessed 13 Sep 2012).

5. Chen Z. The Third Nationwide survey on causes of death. Beijing: The Peking Union Medical College Press, 2008. 
6. Li SC, Schoenberg BS, Wang CC, et al. Cerebrovascular disease in the people's Republic of China: epidemiologic and clinical features. Neurology 1985;35:1708-13.

7. Wang CC, Cheng XM, Sc L, et al. Epidemiological survey of neurological disorders in six urban areas of the people's Republic of China. Zhong-Hua-Shen-Jing-Wai-ke-Za-Zhi 1985;1:2-7.

8. Ahmad OB, Boschi-Pinto C, Lopez AD, et al; GPE Discussion Paper Series: No.31. Age standardization of rates: a new WHO standard: World Health Organization, 2001. http://www.who.int/healthinfo/ paper31.pdf?ua=1

9. Xue GB, Yu BX, Wang XZ, et al. Stroke in urban and rural areas of China. Chin Med J 1991;104:697-704.

10. The Military Epidemiological Collaborative Study Group. Epidemiological study on cerebrovascular disease in China. Beijing: People's military medical press, 1993.

11. Lijun R, Maigeng Z, Lijun W. Present status and development of death cause report. Disease surveillance 2008;23:1-3.

12. Wang Z, Hu S, Sang S, et al. Age-Period-Cohort analysis of Stroke Mortality in China: data from the global burden of disease study 2013. Stroke 2017;48:271-5.

13. Yang G, Wang Y, Zeng Y, et al. Rapid health transition in China, 19902010: findings from the global burden of disease study 2010. Lancet 2013:381:1987-2015.

14. Zhou M, Wang H, Zhu J, et al. Cause-specific mortality for 240 causes in China during 1990-2013: a systematic subnational analysis for the global burden of disease study 2013. Lancet 2016;387:251-72.

15. Analysis of death rates and the causes of death in part of the urban and rural areas in China. Chin J HealthStati 1999;16:276-90.

16. Wu Z, Yao C, Zhao D, et al. Sino-MONICA project: a collaborative study on trends and determinants in cardiovascular diseases in China, Part i: morbidity and mortality monitoring. Circulation 2001;103:462-8.

17. Kim AS, Cahill E, Cheng NT, et al. Geographic variation in stroke burden worldwide. Stroke 2015;46:3564-70.

18. Lackland DT, Roccella EJ, Deutsch AF, et al. American Heart Association Stroke Council; Council on Cardiovascular and Stroke
Nursing; Council on Quality of Care and Outcomes Research; Council on functional genomics and translational biology.factors influencing the decline in stroke mortality: a statement from the American Heart Association/American Stroke Association. Stroke 2014;45:315-53.

19. Parry J. Nine in 10 Chinese are covered by medical insurance, but access to treatment remains a problem. BMJ 2012;344:e248.

20. Liao Y, Gilmour S, Shibuya K. Health Insurance Coverage and Hypertension Control in China: Results from the China Health and Nutrition Survey. PLoS One 2016;11:e0152091.

21. Liu L, Wang D, Wong KS, et al. Stroke and stroke care in China: huge burden, significant workload, and a national priority. Stroke 2011;42:3651-4

22. Wang $Y$, Liao $X$, Zhao $X$, et al. Using recombinant tissue plasminogen activator to treat acute ischemic stroke in China: analysis of the results from the Chinese National Stroke Registry (CNSR). Stroke 2011;42:1658-64.

23. Ma RH, Wang YJ, Qu H, et al. Assessment of the early effectiveness of a stroke unit in comparison to the general ward. Chin Med J 2004;117:852-5.

24. Wang C, Li J, Zhao X, et al. Stroke care development in Mainland China: past, present and future. Int J Stroke 2008;3:288-9.

25. Wang WZ, Jiang B, Liu HM, et al. Minimally invasive craniopuncture therapy vs. conservative treatment for spontaneous intracerebral hemorrhage: results from a randomized clinical trial in China. Int $J$ Stroke 2009;4:11-16.

26. Changlin $\mathrm{H}$, lu Yongtao $\mathrm{L}$, et al. Guidelines of intracranial hematoma Microinvasive Craniopuncture Scavening Technique. Beijing: People's Medical Publishing House, 2014.

27. Jiang $B$, Wang $W$, Chen $\mathrm{H}$, et al. Incidence and trends of Stroke and its subtypes in China. Stroke 2006;37:63-8.

28. Society CS; Chinese Medical Association. Guidelinesof diagnosis and treatment of acute ischemic stroke in China2014. Chinese Journal of Neurology 2015;48:246-57.

29. Society CS; Chinese Medical Association. Guidelinesfor the secondary prevention of ischemic stroke and transient ischemic attack in China 2014. Chinese Journal of Neurology 2015;48:258-73. 